\title{
Determination of Tensile Properties for Twisted Fibre Bundles of Oil Palm Empty Fruit Bunch at Different Diameters
}

\author{
Nik N. Nasri ${ }^{1}$, Nazmi M. Nawi*1, 2,3 ${ }^{\text {, Azhari S. Baharuddin }}{ }^{4}$, Saripa M. Lazim ${ }^{1}$ \\ ${ }^{1}$ Department of Biological and Agricultural Engineering, Faculty of Engineering, Universiti \\ Putra Malaysia, Malaysia. \\ ${ }^{2}$ Institute of Plantation Studies, Universiti Putra Malaysia, Malaysia. \\ ${ }^{3}$ Smart Farming Technology Research Centre, Faculty of Engineering, Universiti Putra \\ Malaysia, Malaysia. \\ ${ }^{4}$ Department of Process and Food Engineering, Faculty of Engineering, Universiti Putra \\ Malaysia, Malaysia. \\ *Corresponding author E-mail: nazmimat@upm.edu.my \\ Received 19 September 2019; Accepted 22 April 2021; Available online 20 August 2021
}

\begin{abstract}
The potential use of natural fibre extracted from oil palm empty fruit bunches has gained wide attention among researchers. This natural fibre comes from fibrous strands which form fibre bundle after shredding process at a mill. The measurement of tensile properties is important to understand the mechanical performance of this fibre bundle. This study was undertaken to determine the tensile properties of the fibre bundle from oil palm empty fruit bunch (OPEFB). Fibrous strands of the OPEFB extracted from shredded empty fruit bunches were twisted to form fibre bundle specimens at different diameters varying from 1 to $5 \mathrm{~mm}$. The tensile properties measured in this study including tensile strength, tensile load and tensile modulus. The measurements were performed using Instron Universal Test Machine (IUTM) model 5000. From the results, it was found that the specimens at 1 and $5 \mathrm{~mm}$ in diameter required 71.25 and $429.68 \mathrm{~N}$ of the tensile load to break, respectively. The specimen with $1 \mathrm{~mm}$ in diameter recorded the highest tensile strength of $90.72 \mathrm{MPa}$ while the specimen with $5 \mathrm{~mm}$ in diameter recorded only $21.88 \mathrm{MPa}$. The highest tensile modulus with value of $662.50 \mathrm{MPa}$ was obtained from the specimen with $1 \mathrm{~mm}$ in diameter while the specimen with $5 \mathrm{~mm}$ in diameter had the tensile modulus value of $157.47 \mathrm{MPa}$. It was also found that the tensile strength and tensile modulus decreased when the diameter of the specimens increased. The findings reported in this study can serve as an engineering basis for the design specification in the development of the future in-silo composting machine.
\end{abstract}

Keywords: Tensile properties, Oil palm, Fibre, Empty fruit bunch, Diameter.

\section{Introduction}

Oil palm (Elaeis guineensis) is one of the most significant crops in Malaysia. Oil palm tree is considered as one of the highest yielding edible oil crops in the world due to its ability to typically produce about 4 to 5.5 ton of palm oil and palm kernel oil per hectare in a single harvest cycle (Hashim et al., 2012). Awalludin et al. (2015) reported that the plantation of oil palm in Malaysia 
covered the area of 5.39 million hectares with 426 palm oil mills were built throughout the country in 2014. In addition, the oil palm industry is the fourth largest sources of the national income and it's contributed over USD22.31 billion to the Malaysian's economy.

One of the critical issues in the palm oil industry is the production of huge amount of biomass waste. The typical wastes which are produced by this industry during the oil palm fruits harvesting, palm oil processing or during oil palm trees replantation were palm kernel shell (PKS), empty fruit bunches (EFB), palm oil mill effluent (POME), mesocarp fibre (MF), oil palm fronds (OPF) and oil palm trunks (OPT) (Awalludin et al., 2015). Typically, the fresh oil palm fruit bunch comprises of $14-15 \%$ fibre, $21 \%$ palm oil, 6-7\% palm kernel, $23 \%$ empty fruit bunch and 6-7\% shell (Umikalsom et al., 1997). Out of that, the EFB is regarded as a cheap and abundant biomass resource which can be utilised as an important feedstock to generate various products such as bio-hydrogen biosyngas, bio-oil, bioethanol, bio-compost and bio-composite (Abdulrazik et al., 2017).

Since several decades ago, numerous studies were carried out to increase the utilization of the EFB. The EFB is lignocellulosic rich material which is suitable for various application such as bio-plastic, natural fibre composite, pulp, source of enzyme and animal feed (Yeoh et al., 2011). Natural fibre composites (NFCs) are attracting attention because they offer different benefits such as low cost, biodegradability, low density, better thermal and insulating properties and low energy consumption during processing (Jawaid et al., 2010). The potential of NFCs to replace synthetic fibre was studied mainly in terms of its mechanical performance, specifically its tensile properties (Gunawan et al., 2009; Yusoff et al., 2009; Jawaid et al., 2010; Omar et al., 2014; Zailuddin \& Husseinsyah, 2016).

Yusoff et al. (2009) determined the mechanical performances and moisture content of a single oil palm fibre with a diameter ranged from 250 to $610 \mu \mathrm{m}$ and 2.2 to $9.5 \%$, respectively. In the study, it was found that the average values of the Young's modulus, tensile strength, and elongation at break were $1703 \mathrm{MPa}, 71 \mathrm{MPa}$, and $11 \%$, respectively. In a similar study, Ramlee et al. (2019) studied physical, tensile and morphological properties of EFB and sugarcane bagasse (SCB) fibre for the fabrication of hybrid composites. The authors concluded that the hybridization of EFB/SCB fibre composites offered better performance and properties as compared to pure fibre composites. Anuar et al. (2019) compared the morphological and mechanical properties of oil palm EFB fibres and kenaf fibres in nonwoven reinforced composites. The study concluded that the EFB has good potential applications as nonwoven fabric and alternative reinforcement material in nonwoven composites.

However, most of the previous researches only studied the tensile properties of an individual fibrous strand. There were no available studies reported the tensile properties of EFB in a form of a fibre bundle. In practice, the EFB discharged from a palm oil mill comes in a bulk and shredded form. Each shredded EFB comprises of thousands of fibre strands which were naturally twisted and mixed together. Therefore, instead of measuring the tensile properties for an individual fibre strand, it is also significant to determine the tensile properties of a bulk and twisted fibre bundle. Tensile properties of a 
bulk fibre bundle will serve as an engineering basis for the design specification in the development of the future an in-silo composting machine, EFB cutting machine and EFB chopping machine. Therefore, the objective of this research was to determine the tensile properties (tensile strength and tensile modulus) of EFB fibre bundles at different diameters.

\section{Materials \& Methods:}

\section{Sample preparation}

In this study, shredded EFB samples were supplied by Prestige Central Management Sdn. Bhd., located in Kok Foh, Bahau, Negeri Sembilan, Malaysia. The shredded EFB contained fibre strand from stalks and spikelet. The samples were randomly taken so that the results obtained from this study would represent the behaviour of all shredded EFB available at the mill. The samples collected from the mill were transported to the laboratory for further analysis. In the laboratory, the shredded EFB samples were first cleaned, sorted and air-dried before the individual fibre strand was extracted.
A scissors was used to cut each fibrous strand at $15 \mathrm{~cm}$ length. The extracted fibrous strand was again cleaned, sorted and airdried, and twisted together to form twisted fibre bundle specimens with a diameter of 1 , 2, 3, 4 and $5 \mathrm{~mm}$ (Fig. 1). The formation of the fibre bundle specimens was made based on a typical diameter of the shredded fibre bundles observed at the mill. The fibre bundles were decreasingly twisted from 0.6, $0.5,0.4,0.3$ to 0.2 twist. $\mathrm{cm}^{-1}$ with the increasing diameters from 1 to $5 \mathrm{~mm}$, respectively. The diameter of the specimens was measured using a vernier calliper. Three specimens were produced for each diameter, producing 15 specimens altogether. The fibre bundles for each diameter were replicated three times so that an average value can be obtained during the testing process. A plastic cable tie was used to tie the specimens at the both ends with the distance between the cable ties was kept at $5 \mathrm{~cm}$. The cable tie was placed at $5 \mathrm{~cm}$ distance apart from each other to prevent slippage during the tensile test.

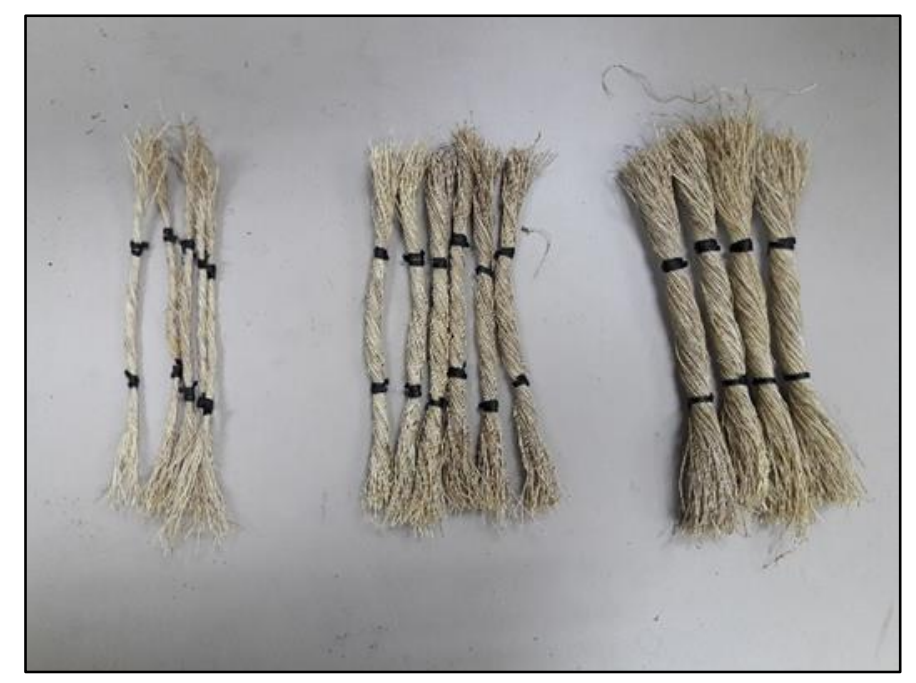

Fig. (1): Specimens of twisted fibre bundles at different diameters. 


\section{Tensile test procedure}

Instron Universal Test Machine (IUTM) Model 5000 with a $5 \mathrm{kN}$ load cell was used to measure the tensile properties of the specimens. A $10 \mathrm{~mm} / \mathrm{min}$ of the crosshead speed was used in this test. All measurements were conducted at the room temperature. All the reported values were the average of three specimens. The specimen was attached to the IUTM at an initial distance of $50 \mathrm{~mm}$ (Fig. 2).

$$
E=\frac{\text { stress }}{\text { strain }}
$$

The stress in the specimens was measured as the tensile strength, MPa and the strain was given by the maximum tensile strain, $\mathrm{mm} / \mathrm{mm}$. Fig. (2 shows how the specimen was placed during the tensile test by the
The test was started with the specimen with 1 $\mathrm{mm}$ diameter, followed by $2 \mathrm{~mm}, 3 \mathrm{~mm}, 4$ $\mathrm{mm}$ and ended with $5 \mathrm{~mm}$. The data were recorded by using the software (Bluehill v2.5, Instron). The software recorded the values of mechanical properties of the specimens such as tensile load $(\mathrm{N})$, tensile strength $(\mathrm{MPa})$, and maximum tensile strain $(\mathrm{mm} / \mathrm{mm})$. Tensile modulus (MPa) was calculated by using Equation (1):

Eqn. 1

UITM to determine the properties of the fibre extracted from the EFB. The data obtained from the tensile test are tabulated in Microsoft Excel for further analysis.

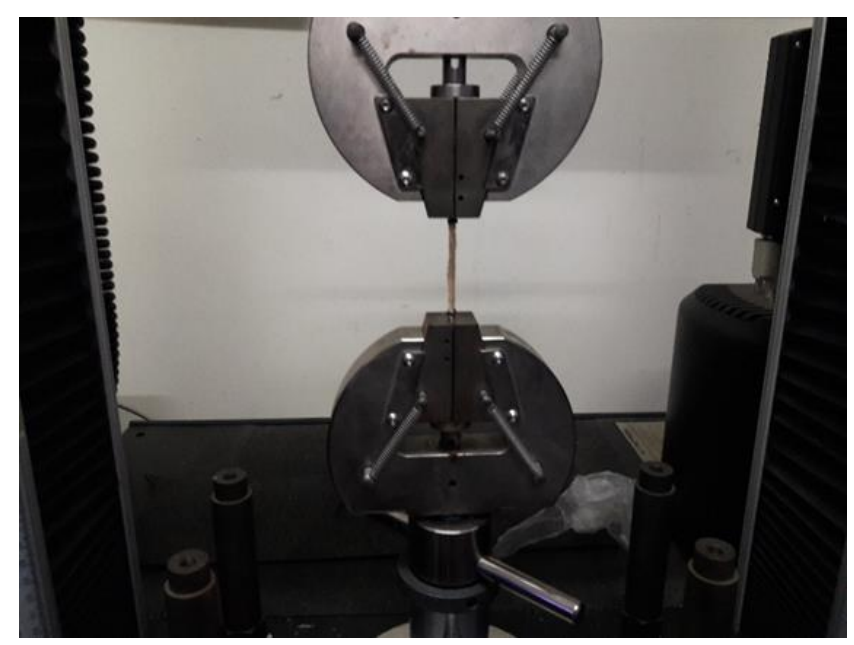

Fig. (2): The specimen during the tensile test by UITM.

\section{Results \& Discussion:}

\section{Tensile properties of the EFB fibre bundles}

The values of mean and standard deviation of the tensile properties in terms of the tensile strength, tensile load and tensile modulus for the EFB fibre bundles at different diameters are shown in (Table 1). The values of the tensile properties for each specimen at different diameters were averaged from three replications. From the table, it is obvious that the tensile properties of the EFB fibre bundles are dependent on the diameter of the specimens. It is clearly shown that the tensile load increases as the diameter of the specimen increased. When the diameter is increased from 1 to $5 \mathrm{~mm}$, the tensile load also increases from 71.25 to $429.68 \mathrm{~N}$, whereas for the tensile strength, the values decrease when the diameter of the specimens 
increased. For example, the tensile strength decreases from 90.72 to $21.68 \mathrm{MPa}$ when the diameter of the specimens increases from 1 to $5 \mathrm{~mm}$. For the tensile modulus, the trend is similar to the tensile strength. The tensile modulus decreases from 662.50 to 157.47 $\mathrm{MPa}$ when the diameter of the specimens increases from 1 to $5 \mathrm{~mm}$.

Table (1): Tensile properties for EFB fibre bundles at different diameters.

\begin{tabular}{ccccccc}
\hline & \multicolumn{2}{c}{ Tensile Load (N) } & \multicolumn{2}{c}{$\begin{array}{c}\text { Tensile Strength } \\
(\mathbf{M P a})\end{array}$} & \multicolumn{2}{c}{$\begin{array}{c}\text { Tensile Modulus } \\
\text { (MPa) }\end{array}$} \\
\cline { 2 - 7 } $\begin{array}{c}\text { Diameter of } \\
(\mathbf{m m})\end{array}$ & Mean & SD & Mean & SD & Mean & SD \\
\hline 1 & 71.25 & 19.62 & 90.72 & 24.9 & 662.50 & 178.14 \\
\hline 2 & 90.54 & 9.15 & 28.82 & 2.91 & 257.15 & 60.40 \\
\hline 3 & 188.02 & 45.45 & 26.60 & 6.43 & 186.69 & 22.10 \\
\hline 4 & 186.29 & 6.09 & 14.83 & 2.48 & 146.73 & 16.52 \\
\hline 5 & 429.68 & 93.12 & 21.88 & 4.74 & 157.47 & 44.51 \\
\hline
\end{tabular}

$* \mathrm{SD}=$ Standard deviation

\section{Tensile load}

Tensile load refers to the force needed to break the specimens under the pulling force. The tensile load recorded for the specimens at different diameters used in this study are shown in the scatter plot as shown in (Fig. 3). The trend of the plot shows that the tensile load increases gradually with the increase in specimen's diameter. For example, specimen at $1 \mathrm{~mm}$ diameter required only $71.25 \mathrm{~N}$ of tensile load while the specimen at $5 \mathrm{~mm}$ diameter required $429.68 \mathrm{~N}$ of tensile load. This data can be used to select an optimum required torque for the cutting machine to break the fibre bundle into small pieces. According to Wong et al. (2008), the tensile load of the fibre depends on many factors such as the length, diameter and filler loading. For example, a longer fibre requires less load to break it as compared to a shorter fibre. In terms of a diameter, a fibre bundle with a bigger diameter will require a higher load to break the samples (Islam et al., 2019). 


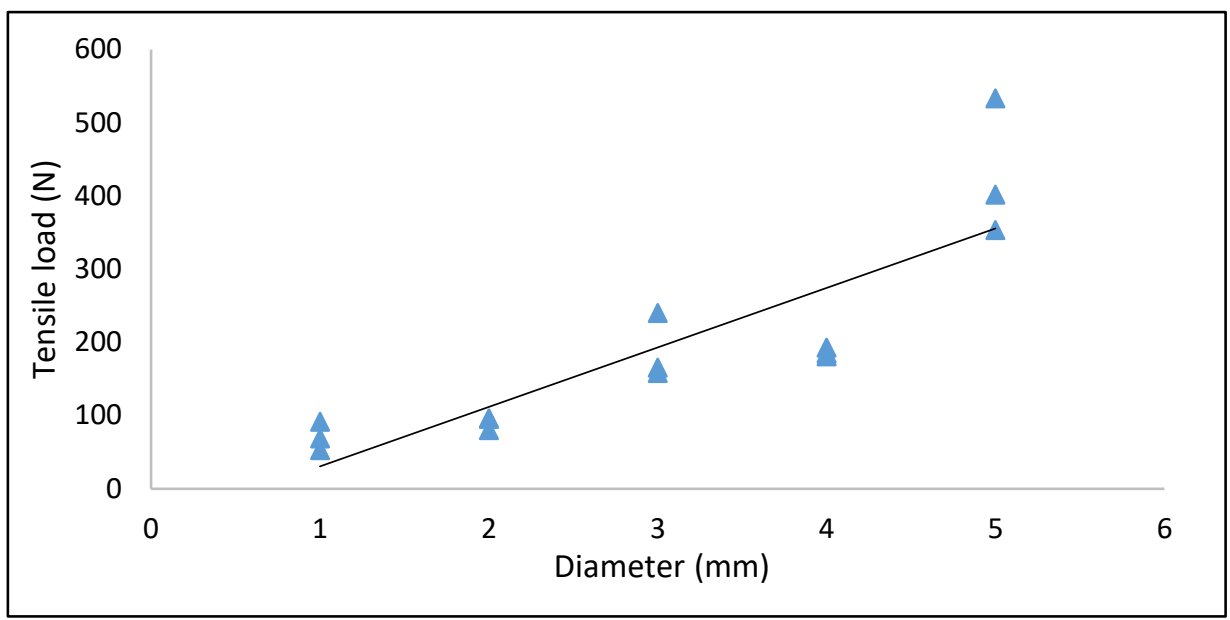

Fig. (3): Tensile load versus EFB fibre bundle diameter.

\section{Tensile strength}

Tensile strength refers to the maximum stress which can be withstood by the specimens during stretching or pulling before breaking. The tensile strength (MPa) for the EFB fibre bundles at different diameters used in this study are shown in the scatter plot as shown in fig. (4). The highest value of the tensile strength was $90.72 \mathrm{MPa}$ belong to the fibre bundle with a diameter of $1 \mathrm{~mm}$. While the lowest tensile strength of $21.88 \mathrm{MPa}$ was recorded for the fibre bundle with $5 \mathrm{~mm}$ diameter. Based on the graph, it can be concluded that the tensile strength decreased as a diameter of fibre bundle increased. Gunawan et al. (2009) and Yusoff et al. (2009) reported the same pattern of tensile strength versus diameter for single strand of EFB fibre. Gunawan et al. (2009) claimed that the trend was due to void present in the larger diameter of the fibre. Apart from that, the non-uniform behaviour of the multiple fibre in the bundled sample might also contributed to the variations of tensile strength obtained from the test.

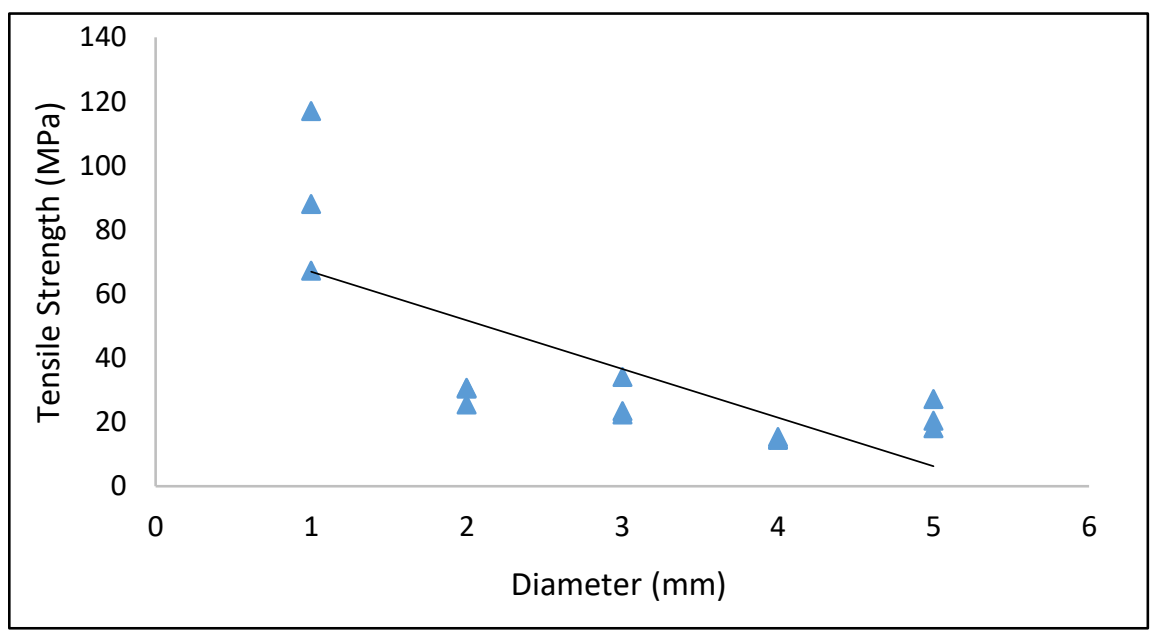


Fig. (4): Tensile strength versus EFB fibre bundle diameter

\section{Tensile modulus}

Tensile modulus or modulus of elasticity is one of the mechanical properties to measure stiffness of the fibre bundles based on the relationship between stress and strain in the specimens. The value of the tensile modulus indicates the ability of the specimens to resist elastic deformation. Fig. (5) shows the tensile modulus of the fibre bundles. The figure demonstrates that the tensile modulus of the fibre bundles drops when the diameter increases. This finding is similar to the study reported by Hassan et al. (2018). According to the study, it was observed that the fibre with a higher diameter contained larger value of porosity so the tensile properties of the fibre samples will be reduced.

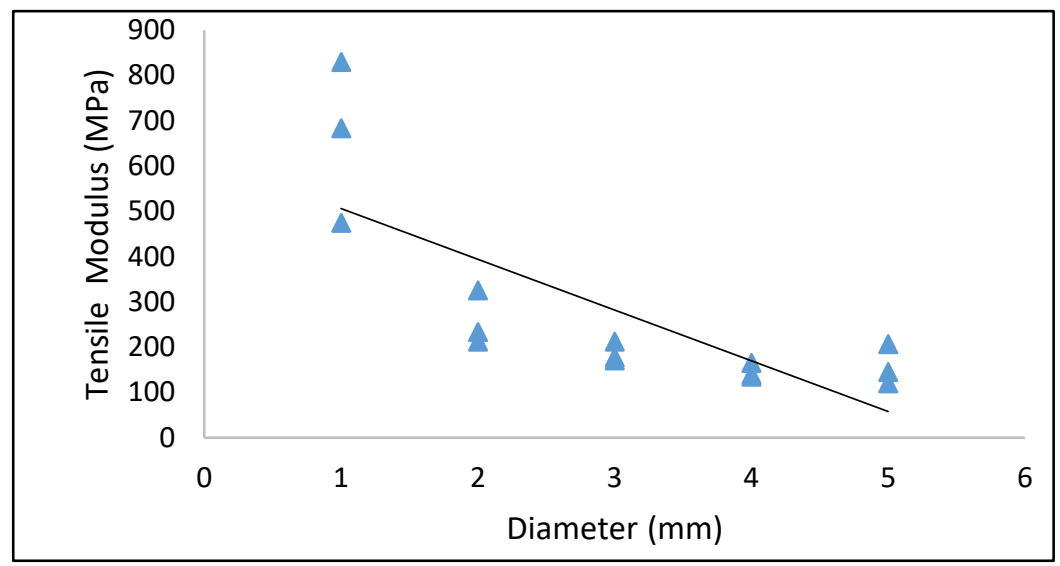

Fig. (5): Tensile modulus versus EFB fibre bundle diameter.

The highest tensile modulus at $662.50 \mathrm{MPa}$ was recorded for the specimen with the diameter of $1 \mathrm{~mm}$. The specimen with $5 \mathrm{~mm}$ diameter had tensile modulus value of 157.47 MPa.

\section{Conclusions}

This study describes the properties of tensile for the twisted oil palm fibre bundle at different diameters. The results show that the specimen with $1 \mathrm{~mm}$ diameter required 71.25 $\mathrm{N}$ of tensile load while the specimen at $5 \mathrm{~mm}$ required 429.68 N. For the tensile strength, the specimen with $1 \mathrm{~mm}$ diameter recorded the highest tensile strength of $90.72 \mathrm{MPa}$ while the specimen with $5 \mathrm{~mm}$ diameter recorded only $21.88 \mathrm{MPa}$. In terms of the tensile modulus, the highest value of tensile modulus was recorded for specimen with 1 $\mathrm{mm}$ diameter while the specimen with $5 \mathrm{~mm}$ diameter had tensile modulus value of 157.47 MPa. From this finding, it was found that the tensile strength and tensile modulus decreased when the diameter of the specimen increased. The findings reported in this study can serve as an engineering basis for the design specification in the development of the future in-silo composting machine.

\section{Acknowledgement:}

The authors acknowledge the financial support provided by Ministry of Higher Education, Malaysia through MyBrain program and Universiti Putra Malaysia for 


\section{Nasri et al./ . Basrah J. Agric. Sci,. 34(Special Issue 1): 149-156, 2021}

providing research grant under Putra Grant Young Researcher Initiative (GP-IPM, Vot no.: 9444100).

\section{References:}

Abdulrazik, A., Elsholkami, M, Elkamel M. A., \& Simon, L. (2017). Multi-products production from Malaysian oil palm empty fruit bunch (EFB): Analyzing economic potentials from the optimal biomass supply chain. Journal of Cleaner Production, 168, 131-148. https://doi.org/10.1016/j.jclepro.2017.08.088

Anuar, N. I. S., Zakaria, S., Gana, S., Chia, C. H., Wang, C., \& Harun, J. (2019). Comparison of the morphological and mechanical properties of oil Palm EFB fibres and kenaf fibres in nonwoven reinforced composites. Industrial Crops and Products, 127, 55-65. https:// doi.org/10.1016/j.indcrop.2018.09.056

Awalludin, M. F., Sulaiman, O., Hashim, R., \& Nadhari, W. N. A W. (2015). An overview of the oil palm industry in Malaysia and its waste utilization through thermochemical conversion specifically via liquefaction. Renewable and Sustainable Energy Reviews. 50, 1469-1484. https://doi.org/10.1016/j.rser.2015.05.085

Islam, F., Joannès S., \& Laiarinandrasana, L. (2019). Evaluation of critical parameters in tensile strength measurement of single fibres. Journal of Composite Science, $\quad 3, \quad 1-17$. https://doi.org/10.3390/jcs3030069

Gunawan, F. E., Homma, H., Brodjonegoro, S. S., Baseri, A., \& Zainuddin, A. (2009). Mechanical properties of oil palm empty fruit bunch fibre. Journal of Solid Mechanics and Material Engineering, 3, 943-951. https://doi.org/10.1299/jmmp.3.943

Hashim, S. N., Sulaiman, R., Ibrahim, O., Sato, M., \& Hiziroglu, S. M. (2012). Optimum manufacturing parameters for compressed lumber from oil palm (Elaeis guineensis) trunks: Respond surface approach. Compos Part B- Eng. 43, 88-96. doi.org/10.1016/j.compositesb.2011.11.002

Hassan, C. S., Sapuan, S. M., Abd Aziz, N., \& Yusof, M. Z. M. (2018). Effect of chemical treatment on the tensile properties of single oil palm empty fruit bunch (OPEFB) fibre. Trends in Textile Engineering \& Fashion Technology. 3, 1-
7. 10.1016/j.compositesb.2012.07.027

Jawaid, M., Khalil, H. P. S. A., \& Bakar, A. A. (2010). Mechanical performance of oil palm empty fruit bunches/jute fibres reinforced epoxy hybrid composites. Materials Science and Engineering, A. 527 , 7944-7949. https://doi.org/10.1016/j.msea.2010.09.005

Omar, F. N., Mohammed, P. M. A., \& Baharuddin, S. A. (2014). Modelling of silica bodies. Bioresources, 9, 938-951.

Ramlee, N. A., Jawaid, M., Zainudin, E. S., \& Yamani, S. A. K. (2019). Tensile, physical and morphological properties of oil palm empty fruit bunch/sugarcane bagasse fibre reinforced phenolic hybrid composites. Journal of Materials Research and Technology, 8, 3466-3474. https://doi.org/10.1016/S0960-8524(97)00132-6

Umikalsom, M. S., Ariff, A. B., Zulkifli, H. S., Tong, C. C., Hassan, M. A., \& Karim, M. I. A. (1997). The treatment of oil palm empty fruit bunch fibre for subsequent use as substrate for cellulase production by Chaetomium globosum Kunze. Bioresource Technology, 62, 1-9. https://doi.org/10.1016/S0960-8524(97)00132-6

Yeoh, C., Chin, N., \& Tan, C. (2011). Co-composting of palm oil mill wastes. Journal of Food, Agriculture and Environment, 9, 880885. http://www.isfae.org/scientificjourna

Yusoff, M. Z. M., Salit, M. S., \& Ismail, N. (2009). Tensile properties of single oil palm empty fruit bunch (OPEFB) fibre. Sains Malaysiana, 38, 525529.

Wong, S. C., Baji, A., \& Leng S. (2008). Effect of fiber diameter on tensile properties of electrospun poly (3-caprolactone). Polymer, 49, 4713-4722. https://doi.org/10.1016/j.polymer.2008.08.022

Zailuddin, N. L. I., \& Husseinsyah, S. (2016). Tensile properties and morphology of oil palm empty fruit bunch regenerated cellulose biocomposite films. Procedia Chemistry, 19, 366-372. https://doi.org/10.1016/j.proche.2016.03.025 